\title{
ABSENCE OF SCAR FORMATION IN INFANTS AFTER BCG VACCINATION.
}

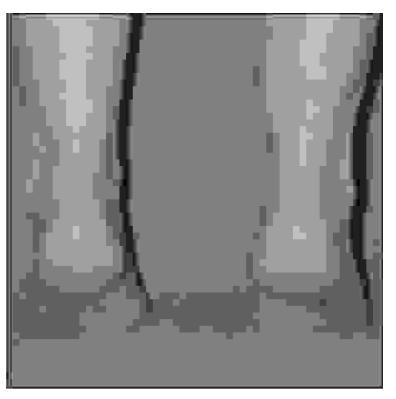

\author{
DR. AHMAD SHERJIL MBBS, FCPS (PAEDS) \\ Child Specialist, \\ PNS Rahat Hospital, Karachi.
}
DR. COL JAVAID IQBAL MBBS, FCPS (GEN. MED)
Head of Medical Department,
PNS Rahat Hospital, Karachi.

\begin{abstract}
Objective: To determine proportion of infants who do not develop BCG scar after vaccination. To highlight importance of evaluation and follow up for these infants. Study Design: Observational Cross-sectional study. Setting: In Vaccination Centre Military Hospital Rawalpindi. Duration: From $1^{\text {st }}$ January 2003 to $15^{\text {th }}$ March 2003. Materials \& Methods: 50 to 70 infants are vaccinated in the hospital every day. Infants fulfilling the inclusion criteria averaged ten per day during this study. It took two and a half month, to complete a random sample of 250 infants. Sample Size: 250 vaccinated infants. Results: Of all the infants, first 250 infants who fulfilled the laid down criteria were documented. Two hundred and one infants, males and females showed presence of scar. Forty-nine infants, males and females showed no response to BCG vaccination. Conclusion: This descriptive study concludes that a significant proportion of infants does not show tuberculin reactivity after vaccination and need monitoring and evaluation for causes of poor reactivity e.g. poor technique, quality of vaccine, improper storage as well as underlying undiagnosed immunological disorders.
\end{abstract}

Key words: $\quad$ Tuberculosis, BCG, Vaccination, Scar, Intradermal

\section{INTRODUCTION}

BCG is the most widely used vaccine in the world and has been administered to over 2.5 billion people with a low incidence of complications ${ }^{1,2,6}$. It is cheap, can be given any time after birth, sensitizes the vaccinated individual for five to fifty years and stimulates both B cell and $T$ cell immune responses ${ }^{9}$. BCG vaccination in infants offers immunity against severe forms of tuberculosis in 50\%-80\% cases and pulmonary tuberculosis in $50 \%$. Official recommendation of World
Health Organization is single administration of BCG vaccine in infancy ${ }^{10}$. Many local studies, including Mazhar et al ${ }^{1}$, Manzoor et al ${ }^{4}$, Butt et al ${ }^{6}$ and Nizami et al in Karachi ${ }^{7}$ mentioned BCG vaccination as an important preventive method against tuberculosis and described BCG scar an important indicator of vaccine uptake.

Tuberculin reactivity is seen as scar formation which develops within 1 to 3 months after BCG vaccination ${ }^{13,14}$. Some infants do not develop a scar after vaccination. 
The importance of this study lies in the fact that it highlights ineffective vaccination and the need to take appropriate measures to evaluate such infants.

While a lot has been studied about tuberculin reactivity, little local work has been done for subjects who show no reactivity ${ }^{9,11,12}$. My study focuses on determining proportion of these vaccinated infants who do not develop BCG scar, in a random sample of vaccinated subjects.

\section{MATERIALS AND METHODS}

Study was carried out at vaccination centre Military Hospital Rawalpindi. Here neonates are routinely given BCG vaccination within one week of birth and brought back to this vaccination centre for DPT vaccination and oral Polio vaccination at six, ten and fourteen weeks of age. It was at fourteen weeks of age when a random sample of 250 infants was documented for absence as well as formation of scar. Older infants, fulfilling the laid down criteria were also documented. A carefully designed Proforma was used for documentation.

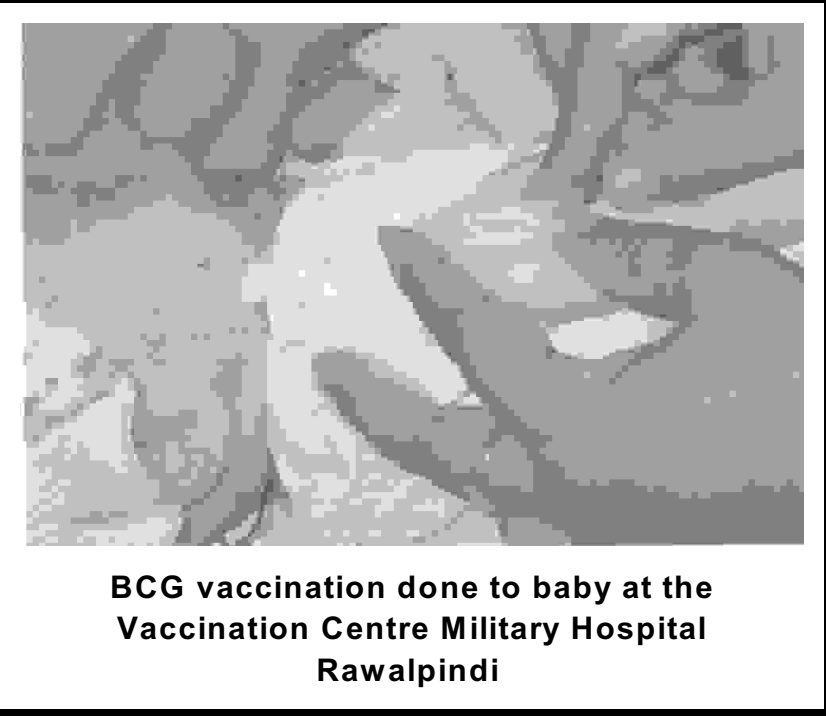

\section{Material}

Live, freeze dried BCG vaccine marketed by Intervax Ltd
Canada, manufactured by BB-NCIPD Ltd, Bulgaria was used .It was stored at 2-8 C. It is composed of $0.5 \mathrm{mg}$ BCG and $3.0 \mathrm{mg}$ of Na- Glutamate. Single dose is 0.05 $\mathrm{ml}$ given intradermal. Vial contains up to 20 doses after diluting the vaccine with $1 \mathrm{ml}$ diluent.

\section{Inclusion Criteria}

1. Infants born in Military Hospital with,

$$
\begin{array}{ll}
\text { a. } & \text { Regular antenatal checkup } \\
\text { b. } & \text { Spontaneous vertex delivery }
\end{array}
$$

2. Vaccinated at Military Hospital

3. Full term appropriate for gestational age at birth

4. At least $3 \frac{1}{2}$ months old if vaccinated at birth , at the time of documentation.

5. Vaccinated at least 3 months back if older than $3 \frac{1}{2}$ months

\section{Exclusion Criteria}

1. Mothers with any immune disorder

2. Tuberculin reactivity of any degree after BCG vaccination

3. Complicated pregnancy

4. Complicated delivery

5. Congenital Anomalies

6. Natal/postnatal complications

7. Admission after birth in nursery for any reason

8. Age less than $3 \frac{1}{2}$ months

\section{Statistical Technique}

No statistical test is applicable here because study design was descriptive. However proportion and percentage has been measured along with standard error and 95\% Confidence Interval.

\section{PROCEDURE}

All newborns delivered in Military hospital Rawalpindi were given BCG vaccination within one week of birth and parents were handed over vaccination cards. Infants were brought back to Military Hospital vaccination centre for DPT vaccination and oral Polio vaccine at six, ten and fourteen weeks of age. It was at fourteen weeks of age, 
when we documented 250 infants for absence as well as formation of scar. Older infants, vaccinated at least three months back, fulfilling the laid down criteria, were also documented. Documentation was carried out from $31^{\text {st }}$ January to $30^{\text {th }}$ March 2003. All subjects were documented by convenience sampling.

\section{RESULTS}

Of all the infants, first 250 infants who fulfilled the laid down criteria were documented from $1^{\text {st }}$ January 2003 to $15^{\text {th }}$ March 2003. Two hundred and one infants, males and females showed presence of scar. Forty-nine infants, males and females showed no response to BCG vaccination. This proved that a significant proportion i.e. $19.6 \%$ or almost one fifth of all subjects needed further evaluation.

Percentage of infants without scar $=19.6$

$$
\begin{aligned}
\text { Standard Error } & =\sqrt{=\frac{p(10 \phi-2 p l}{n}} \\
& =\sqrt{\frac{-196(104-1) 6)}{48}}=567
\end{aligned}
$$

\section{Graphic presentation of results}

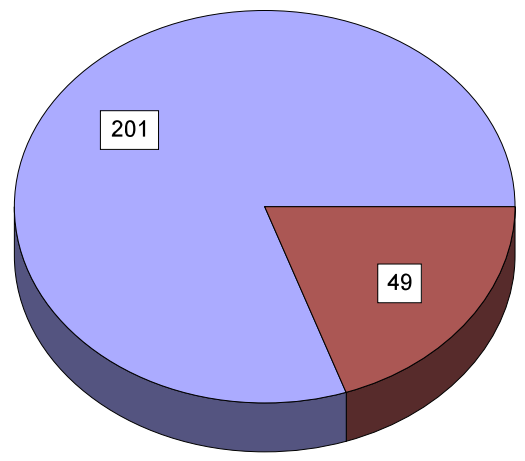

Scar present

Scar absent

where,$p=$ percentage under consideration (i.e. percentage of infants without BCG scar) $n=$ number of subjects in the sample (without scar) 95\% Confidence Interval $=p \pm(2 x$ standard error $)$
$=19.6 \pm(2 \times 5.67)$

$=8.26$ to 30.94

\begin{tabular}{|l|c|c|c|c|}
\hline \multicolumn{5}{|c|}{ Results in tabulated Form } \\
\hline & $\begin{array}{c}\text { No. of } \\
\text { Infants }\end{array}$ & $\begin{array}{c}\text { Scar } \\
\text { present }\end{array}$ & $\begin{array}{c}\text { Scar } \\
\text { Absent }\end{array}$ & $\begin{array}{c}\% \text { age } \\
\text { without } \\
\text { scar }\end{array}$ \\
\hline $\begin{array}{l}\text { Male infants } \\
\text { examined } \\
\text { ubfabts } \\
\text { exanubed }\end{array}$ & 148 & 119 & 29 & 19.59 \\
\hline Female & 102 & 82 & 20 & 19.61 \\
\hline Total & 250 & 201 & 49 & 19.60 \\
\hline
\end{tabular}

* Total number of infants selected by random sampling - 250 .

* Total number of infants who showed reaction to vaccination -- 201.

* Total number of infants who showed no response to vaccination -49 .

* Percentage of infants with absence of scar formation after BCG vaccination - 19.6\%.

\section{DISCUSSION}

The goal of this study was to find concrete evidence of the fact that a significant proportion of infants does not develop BCG scar after vaccination and, therefore, need attention because of this improper uptake of BCG vaccine, whatever the reason may turn out to $b e^{8,9,10}$. The aim was to emphasize complete and proper BCG vaccination because it is an important instrument for prevention of severe form of tuberculosis in our country on community level $\left.\right|^{1,2,4,5,6}$.

Results did reveal a significant proportion of BCG vaccinated infants without scar formation, a finding which was in accordance with the initial presumption that absence of scar formation after BCG vaccination is not just an observation of parents of affected infants. 
Study implies that quality of vaccine, proper vaccine transport and storage need attention. There can also be an undiagnosed underlying immune disorder in these infants, responsible for absence of scar formation ${ }^{5,8}$.

Local research work does mention absence of BCG scar as an undeniable observation ${ }^{1,2,3,4,5,6,7,11,14}$ and emphasized on investigating such cases but does not mention an exact figure or proportion for such infants (which was the objective of this descriptive study).

However, many Indian studies are available that mention BCG scar as an important indicator of immunization against tuberculosis and provide survey of appearance of BCG scar in infants. Kaur et al in Delhi ${ }^{8}$ carried out a study regarding appearance of BCG scar in neonates of varying gestational ages. This study mentions the appearance of BCG scar in about $60 \%$ of all subjects, three months after vaccination. In this study, babies were observed in a hospital setting but were vaccinated at more than one place. Compared to this Indian study, our study shows a better result, probably because vaccination in our subjects was done in a single tertiary care hospital setting.

A survey of findings of BCG scar was done by Indian National Tuberculosis Institute in Bangalore city ${ }^{10}$. BCG scar was identified in 71 percent and 74 percent of the children aged 12 to 23 months and 5 to 7 years respectively. The scar could not be identified among 20 percent of the children vaccinated according to immunisation cards. This study shows results almost similar to our study.

Another study carried out by Channabasavaiah et al in Banglore city, India ${ }^{10}$. aimed at proving effectiveness of $B C G$ vaccination in tuberculosis control. $26.4 \%$ children up to age 12 year did not show vaccine uptake. This survey also supports findings of our study, despite the fact that our study was carried out on a very small scale.
Pereira SM and colleagues found out a percentage of 17.7 in a similar study in Portugal ${ }^{16}$. Garly et al mentioned $17 \%$ BCG vaccinated infants not to have shown scar formation in a study done in Spain ${ }^{17}$.

This study has many limitations including a small sample size collected over a brief period of time. No record of parents was available who did not return after initial vaccination of their infants. Once infants were documented for improper vaccine uptake, they were not followed, monitored and evaluated for cause of vaccination failure (beyond the scope of this study).

\section{CONCLUSION}

This descriptive study concludes that a significant proportion of infants does not show tuberculin reactivity after vaccination and that there is a need to emphasize evaluation and monitoring of these infants ${ }^{2,3,5,14,16}$. Even a small sample of 250 infants collected over a short period of two and a half months showed that about nineteen percent of vaccinated infants were without a BCG scar. It indicates that a survey conducted for an appropriate duration can reveal the true magnitude of problem $^{12,13,14}$.

Based on this study recommendations include, firstly to pay due attention to the quality of BCG vaccine, its handling, techniques of application, the training of personnel and the coverage of eligible population.

Secondly, the need for proper evaluation and monitoring of the BCG vaccination programme is of paramount importance. There should be organized operational research activities in order to yield information that could be used for improving the effectiveness of BCG programmes $^{8,9}$.

Thirdly, one important object of such research is to devise methods for detecting and defining local factors of possible epidemiological relevance in situations in which scarce resources prevent more precise 
epidemiological surveillance ${ }^{9,14}$.

Forth, BCG vaccination should not be considered in isolation as a means of tuberculosis control but should form part of a comprehensive control programme that includes case detection and treatment ${ }^{8,14}$ also.

\section{REFERENCES}

1. Mazhar A, Sarwar MSA. A survey of tuberculin test after BCG vaccination in children. J Coll Phys Surg Pakistan 1995, (2):64-6.

2. Khan $\mathrm{MH}$. Tubercolsis: need to revitalize its programme in Pakistan (editorial). J Coll Phys Surg Pakistan 1996, 1(6): 3.

3. Pathan AJ. Next century of tuberculosis control in Pakistan. J Chest Med 2000; 6 (2):7-8.

4. Manzoor H. Tuberculosis-a hope to control (editorial). Med Spectrum 2000; 21(9):1.

5. Ahmad SR, Bokhari SY. Anergy in pulmonary tuberculosis. Pakistan J Chest Med 2000, 6(2):5-9.

6. Butt MA et al. Pattern of tuberculosis in immunized and nonimmunized children. Ann KF. Med Coll 1998, 4 (3):24-6.

7. Nizami SQ. Childhood tuberculosis (editorial). J Pakistan Med Assoc 1998, 48(4):8.

8. Kaur S, Faridi MM. BCG vaccination reaction in low birth weight infants. Indian J Med Res.2002 Aug;116:64 9.
9. Chadha VK, Murthy MSK, Shashidhara AN. Findings of BCG scar survey in Bangalore city. Indian Journal of Preventive and Social Medicine.1997 July28(3):81-9. July, 40(3):137-44.

10. Channabasavaiah R, Muralimohan V. Waning of BCG scar and its complications. Indian Journal of Tuberculosis;1993 July,40(3):137-44.

11. Khan UA. Tuberculosis control in Pakistan. Pak J Chest Med 2001;7(1) Suppl :37-9.

12. Brundtland $\mathrm{GH}$. Goals and objectives for tuberculosis control. Pak J Chest Med 2001:7(1):13.

13. Habibullah S, Rizvi N, Zaidi AH. BCG vaccination of children up to age 12 years: does it protect against tuberculosis? Specialist 1999:15(2):113-7.

14. Hussain $S$, Yaccub AAH. Distribution of tuberculin reaction among children at school entry. Med Spectrum 1997, 18(10):15-7.

15. Arain GM. BCG vaccination(editorial) J Pakistan Med Assoc 1991, 41(7):150-1.

16. Pereira SM et al. Sensitivity and specificity of the BCG scar reading. Rev Saude Publica 2003 Apr 04.

17. Garly ML et al. BCG scar and positive tuberculin reaction associated with reduced child mortality in West Africa. A non-specific beneficial effect of BCG? Vaccine. 2003 Jun 20;21(21-22):2782-90. 